\title{
Effect of Long-Term Storage on Microstructure and Microhardness Stability in OFHC Copper Processed by High-Pressure Torsion
}

By Abdulla I. Almazrouee*, Khaled J. Al-Fadhalah, Saleh N. Alhajeri, Yi Huang, Terence G. Langdon

[*] Dr. A. I. Almazrouee, Dr. S. N. Alhajeri

Department of Manufacturing Engineering, College of Technological Studies, P.A.A.E.T., P.O.

Box 42325, Shuwaikh 70654, Kuwait

E-mail: ai.almazrouee@paaet.edu.kw

Dr. K. J. Al-Fadhalah

Department of Mechanical Engineering, College of Engineering \& Petroleum, Kuwait University, P.O. Box 5969, Safat 13060, Kuwait

Dr. Y. Huang

Department of Design and Engineering, Faculty of Science and Technology, Bournemouth University, Poole, Dorset BH12 5BB, UK

Materials Research Group, Department of Mechanical Engineering, University of Southampton, Southampton SO17 1BJ, UK

Prof. T.G. Langdon

Materials Research Group, Department of Mechanical Engineering, University of Southampton, Southampton SO17 1BJ, UK

Departments of Aerospace \& Mechanical Engineering and Materials Science, University of Southern California, Los Angeles, CA 90089-1453, USA

Keywords: copper, high-pressure torsion, microhardness, recrystallization, ultrafine grains

Abstract

Tests are conducted to evaluate the effect of long-term storage on the microstructure and microhardness of an oxygen-free high conductivity (OFHC) copper after processing by high-pressure torsion (HPT) for various numbers of revolutions at ambient temperature.

Results are presented for samples subjected to storage at room temperature through periods of either 1.25 or 7 years. The results show that an increase in storage time leads to a coarsening of the ultrafine-grained structure produced by HPT processing and a corresponding decrease in the microhardess where this is associated with the occurrence of recrystallization and grain growth. Plots of hardness against equivalent strain reveal a three-stage behavior with much lower hardness values over a range of equivalent strains of $\sim 2-8$. This behavior is similar after both storage periods but the hardness values are lower and the grain sizes are larger after 
storage for the longer time. The results demonstrate that long-term storage has a significantly detrimental effect on the microstructure and hardness of ultrafine-grained $\mathrm{OFHC} \mathrm{Cu}$ 


\section{Introduction}

Over the last two decades there have been many developments in the processing of ultrafine-grained (UFG) and nanocrystalline materials using severe plastic deformation (SPD). Although several SPD processes are now available, high-pressure torsion (HPT) is especially effective for achieving UFG structures exhibiting superior strength and hardness. ${ }^{[1,2]}$ In HPT, a thin disk is subjected to a high compressive pressure combined with concurrent torsional straining. Microstructural refinement is then achieved with increasing torsional strain and this leads to the formation of a submicrometer or nanometer grain structure with a high fraction of grain boundaries having high angles of misorientation. ${ }^{[3-5]}$ This type of processing is also readily available for the production of materials having superplastic properties. ${ }^{[6]}$ In addition, HPT has been used to induce different phase transformations in SPD materials, such as decomposition of supersaturated solid-solution and the dissolution of precipitates in $\mathrm{Cu}$-based alloys. ${ }^{[7]}$

In practice, the microstructural development is affected by the equivalent von Mises strain, $\varepsilon_{\mathrm{ev}}$, which is given by the relationship ${ }^{[8]}$

$$
\varepsilon_{\mathrm{ev}}=\frac{2 \pi N r}{h \sqrt{3}}
$$

where $N$ is the total number of turns, $r$ is the radial distance from the center of the disk and $h$ is the height (or thickness) of the disk. It is readily apparent from Equation (1) that the strain varies across the disk from a minimum value at the center to a maximum at the edge and this leads to variations in the microstructural development and to an associated hardness inhomogeneity. Generally, there is a gradual evolution in hardness towards a saturation condition with increasing numbers of turns and with the occurrence of maximum hardness values at or very near the disk edge. ${ }^{[9-11]}$ A comprehensive review of the hardening behavior in HPT processing showed that in most materials the hardness ultimately levels off at a saturation value $^{[12]}$ but there are also other results showing deviations from this behavior including the 
occurrence of a softening after a short period of storage due to recovery and self-annealing. ${ }^{[13-}$

${ }^{17]}$ For example, in OFHC copper processed by HPT there was recrystallization in some regions of the deformed structure especially after small numbers of HPT rotations. ${ }^{[13]}$ This was further analyzed by examining the texture development and it was shown that there was a mixture of shear and recrystallization texture components after low to medium HPT strains whereas there was a simple shear texture after high strains. Other results show the development of dynamic recrystallization in HPT hot-deformed samples of pure copper having different purities ${ }^{[18]}$ and in pure $\mathrm{Cu}$ severely deformed by HPT or equal-channel angular pressing (ECAP). ${ }^{[19]}$

OFHC copper was examined after HPT and storage at room temperature for periods of up to 4 weeks, ${ }^{[16]} 6$ weeks ${ }^{[15]}$ and 6 months ${ }^{[17]}$ and it was shown that there was a hardness drop in the recrystallized regions after very small HPT strains, $\varepsilon_{\mathrm{eq}}<20$, whereas at higher strains the UFG microstructures were stable over the whole disk and no hardness reductions were recorded. ${ }^{[15]}$ Nevertheless, very little information is available on the long-term thermal stability of microstructures generated by HPT processing, especially after storage at room temperature for several years. For OFHC $\mathrm{Cu}$ processed by ECAP and HPT after 4 years of storage it was shown that in ECAP the long-term storage reduced the vacancy concentration but the crystallite size and dislocation structure remained unchanged whereas in HPT there was an increase in the grain size and the twin boundary frequency but a corresponding decrease in the dislocation density. ${ }^{[20]}$ The use of HPT at cryogenic temperatures (as at $100 \mathrm{~K}$ ) for different pure metals and alloys showed that short-term storage of 5 hours at room temperature caused self-annealing in pure copper and led to a significant drop in hardness. ${ }^{[21]}$ A recent investigation examined the long-term thermal stability of two alloys and fifteen pure metals after HPT and showed that metals having moderate melting temperatures, such as pure silver, gold and copper, were vulnerable to softening by self-annealing after long-time storage and the long-time stability was weakened when the material had a low stacking fault energy (SFE) such as silver or when it was processed under higher pressures, to higher strains or at lower temperatures. ${ }^{[22]}$ 
Self-annealing in electroplated copper is a critical problem in the printed circuit board (PCB) industries, resulting in microstructure transition due to recrystallization and grain growth at room temperature and therefore leading to a deterioration of its electrical and mechanical properties. ${ }^{[23]}$ Information on the thermal stability of UFG microstructures produced by HPT is an essential requirement for making use of these materials in any future practical applications. For materials processed by SPD, the thermal stability of UFG materials is strongly dependent upon the amount of stored energy introduced during the deformation. Consequently, numerous factors affect the thermal stability including the nature and volume fraction of the lattice defects, the melting temperature, the SFE, the purity level of the material, and the temperature and pressure applied during processing. Post recrystallization and grain growth driven by selfannealing will reduce the strength of the HPT-processed material and may lead therefore to premature failure during service. Furthermore, this problem becomes especially important in high-purity metals having low to medium melting temperatures, such as OFHC copper, which are known to exhibit low thermal stability after room temperature storage. Accordingly, the present investigation was initiated to provide the first comprehensive examination of the longterm stability of the microstructure and the microhardness of OFHC Cu processed by HPT and then stored at room temperature for several years. In this report, some experimental data are presented for samples stored through the relatively short-term of 15 months (1.25 years) but the main emphasis is placed on data obtained from samples processed by HPT and then subjected to long-term storage at room temperature for a period of 7 years.

\section{Experimental material and procedures}

The experiments were carried out using an oxygen-free high conductivity (OFHC) copper of $99.99+$ wt.\% purity having the same chemical composition as in an earlier study. ${ }^{[14]}$ The HPT samples were prepared from a rod of $10 \mathrm{~mm}$ diameter which was annealed at $673 \mathrm{~K}$ for one hour and then cut into disks of $1.0 \mathrm{~mm}$ thickness and polished by abrasive papers on both sides to final thicknesses of $\sim 0.8 \mathrm{~mm}$. All disks were processed by HPT at ambient 
temperature under quasi-constrained conditions ${ }^{[24]}$ with an imposed pressure of $6.0 \mathrm{GPa}$ and a rotational speed of $1 \mathrm{rpm}$. These disks were processed through different numbers of rotations, $N$, from $1 / 4$ to 10 turns. Thereafter, the samples were stored at room temperature and some were examined after 1.25 years but most were finally examined after storage through 7 years.

Standard metallographic techniques were used to obtain mirror-like surfaces on the disks. The disks were then etched at ambient temperature using a mixture of $50 \mathrm{ml}$ of distilled water and $50 \mathrm{ml}$ of nitric acid and examination was undertaken using a Zeiss optical microscope (Axio-Imager). Analysis by electron back-scatter diffraction (EBSD) was also carried out for microstructural evaluation after electropolishing in a solution of $25 \%$ phosphoric acid, $20 \%$ ethanol and $10 \%$ propanol in water. The grain boundary structure was analyzed using an Oxford EBSD detector (Aztec) and interfaces were examined using a JEOL field-emission scanning electron microscope operating at $20 \mathrm{kV}$ (JSM-7001F). The EBSD evaluations were made at three locations on the disk plane: the center, mid-radius and radius (or near-edge) positions and EBSD maps were constructed using step sizes in the range of $0.1-1.0 \mu \mathrm{m}$ in order to incorporate the microstructural evolution at different length scales. The statistics of the distributions of the misorientation angles were analyzed using a critical misorientation angle of $15^{\circ}$ between lowangle boundaries (LABs) and high-angle boundaries (HABs). In the EBSD maps, the LABs are shown as thin grey lines, the HABs as solid black lines and the $\Sigma 3$ twin boundaries as solid red lines. The average grain sizes and grain size distributions were obtained from the EBSD software.

Vickers microhardness (Hv) measurements were taken on the polished surfaces using a Buehler Vickers microhardness tester (MicroMet) with a load of $200 \mathrm{gf}$ and dwell times of 15 s. The positions of the indentations were illustrated previously ${ }^{[14]}$ where measurements were taken along four diameters arranged at $45^{\circ}$ increments with the measurements separated by 0.25 $\mathrm{mm}$ up to distances of $2.0 \mathrm{~mm}$ from the center and at $0.5 \mathrm{~mm}$ thereafter. The microhardness of the annealed unprocessed sample was also measured at different positions on the disk and these 
data were also plotted together with results presented earlier after storage for 1.25 years. Finally, the average Vickers microhardness values were plotted against equivalent strain where the latter was estimated using equation (1).

\section{Experimental results}

\subsection{Microstructural Evolution}

The microstructure of the annealed unprocessed $\mathrm{Cu}$ was described earlier ${ }^{[14]}$ where it was shown that the grains were relatively large with an average grain size of $\sim 15.5 \mu \mathrm{m}$ and there was also a high fraction of annealing twins of $\Sigma 3$ boundaries. Processing by HPT under an applied pressure of $6.0 \mathrm{GPa}$ led to a grain size of $\sim 280 \mathrm{~nm}$ at the edge of the disk after 10 turns.

Figure 1 presents detailed EBSD maps of the microstructures of the $\mathrm{Cu}$ samples after HPT processing and holding in storage at room temperature for 7 years where the five columns are for samples processed through $N=1 / 4,1 / 2,1,5$ and 10 turns and the three rows correspond to the center, mid-radius and radius positions, respectively. The results in Figure 1 show that the degree of microstructural homogeneity increases with both increasing numbers of turns and increasing radial distance. However, due to the long-term storage of 7 years the relatively homogenous UFG microstructure which was reported at the radius position after 10 turns ${ }^{[14]}$ changes into a duplex structure consisting of an array of ultra-fine grains with HABs and scattered recrystallized regions of coarse grains that are highly populated by $\Sigma 3$ boundaries.

The measured fractions of HABs and $\Sigma 3$ boundaries are summarized in Table 1 after storage for 7 years together with data recorded after storage for 1.25 years. It is readily apparent that recrystallization occurred during the storage from 1.25 to 7 years and this is especially demonstrated by the increase in the fraction of the $\Sigma 3$ boundaries with increasing storage time. Thus, in the early stages of HPT processing at $N=1 / 4$ turn the fraction increases from 3.0 to $34.5 \%$ and from 59.0 to $78.9 \%$ for the center and radius positions, respectively. There is also a similar increase in the fraction of HABs at the center and radius positions but, by contrast, the fractions of $\Sigma 3$ boundaries and HABs at the mid-radius position for $N=1 / 4$ turn decreases from 
49.0 to $44.5 \%$ and from 76.0 to $59.7 \%$, respectively. The fractions of both HABs and $\Sigma 3$ twin boundaries generally increase after 1, 5 and 10 turns for 7 years storage at all three observation points.

A summary of the average grain sizes is given in Table 2 after storage for 1.25 and 7 years. These results show that the smallest grain sizes are produced at the radius position after 1,5 and 10 turns where the saturation values are of the order of $\sim 0.3$ and $\sim 0.7 \mu \mathrm{m}$ after 1.25 and 7 years, respectively. Thus, there is significant grain coarsening during long-term storage and this demonstrates that the long-term thermal stability of the UFG structure of high purity copper processed by HPT is partially lost due to self-annealing and the concurrent occurrence of recrystallization and grain growth.

\subsection{Microhardness Measurements}

The radial profiles of the average Vickers microhardness values are plotted in Figure 2 for copper samples processed by HPT through various numbers of turns and then stored for 7 years: the average Vickers microhardness of the as-annealed unprocessed sample was $\sim 48 \mathrm{Hv}$ as shown by the lower line in Figure 2. For the samples processed by HPT and then stored, there are significant variations in the microhardness from a maximum of $\sim 120 \mathrm{Hv}$ to a minimum of $\sim 67 \mathrm{Hv}$ for samples processed with $N \leq 1$ turn. At $N=1 / 4$ turn, there is a softening in hardness primarily towards the edges of the disk whereas the center region has higher values with hardness peaks occurring at $\sim 115 \mathrm{Hv}$ at the $\pm 1.5 \mathrm{~mm}$ positions. At $N=1$ turn the hardness begins to increase at the disk edge but the hardness in the center region drops to a minimum of $\sim 80 \mathrm{Hv}$ for $N=5$ turns and increases to a saturation close to $\sim 120 \mathrm{Hv}$ towards the edges of the disk. The hardness profile for $N=10$ turns looks similar to that obtained after 5 turns except that the hardness values are higher with a saturation of $\sim 125 \mathrm{Hv}$.

Since the recorded hardness values after 1.25 and 7 years are fairly similar in terms of their variation in distance along the diameter, it is easiest to present the results as in Figure 3 where each plot contains data after different numbers of turns for storage through 1.25 and 7 years: 
thus, the results in Figure 3 are for (a) 1/4, (b) 1/2, (c) 1, (d) 5 and (e) 10 turns. First, it is important to note that, although taken in isolation these variations in hardness look unusual, there is an excellent consistency between the datum points recorded after 1.25 and 7 years with both sets of data following identical trends. Second, for all experimental conditions the hardness values recorded after 7 years are lower than those recorded after 1.25 years and, depending upon the numbers of turns and the radial positions, the hardness drops are in the range of $\sim 10-40 \mathrm{Hv}$.

\section{Discussion}

\subsection{Effect of Self-Annealing on Microstructural Development}

Previous results on the HPT of OFHC copper showed a rapid development in microstructural evolution in the early stages of straining along the radial positions of the disks $^{[13-17]}$ with recrystallization and abnormal grain growth occurring extensively in the early stages of straining at $N \leq 1$ turn. This behavior in the early stages of HPT straining matches results reported for pure copper when using a repetitive upsetting-extrusion process. ${ }^{[25]}$ With increasing HPT strain, it is apparent from Figure 1 that a more homogeneous structure develops with fewer small scattered recrystallized regions for samples processed by 5 and 10 turns. At these high strain levels, the grain size was $\sim 300-400 \mathrm{~nm}$ after storage for 1.25 years but this increased to $\sim 700 \mathrm{~nm}$ after storage for 7 years.

Figure 4 provides a direct comparison of the sizes of the recrystallized grains in the samples processed by HPT for 5 and 10 turns and stored for 1.25 years (upper row) and 7 years (lower row). Thus, the fractions and sizes of the recrystallized grains increase with increasing storage time up to 7 years and this gives a duplex structure of large recrystallized grains, characterized by twin $\Sigma 3$ boundaries, and a UFG structure with random but predominantly highangle grain boundaries. Generally, the radius position has a higher fraction of recrystallized grains compared to the mid-radius position and this is due to the higher strain in this region and the corresponding increase in the stored energy. Straumal et al. ${ }^{[26]}$ reported that faceted CSL 
boundaries, such as many of the $\Sigma 3$ twin boundaries, typically have low mobility and their migration leads to abnormal grain growth. This might explain the slow growth of the ultra-fine grains during the long-term storage of HPT-processed copper disks, resulting in a bimodal grain size distribution as shown in Figure 1.

These results show that self-annealing continues to affect the UFG structure even after long storage times. Furthermore, the change in microstructure due to self-annealing is essentially similar for all samples and at all three radial positions. The continuous increase in the average grain size due to recrystallization and grain growth confirms the effect of selfannealing even after 7 years of storage. It has been suggested that dynamic recrystallization may occur in pure copper processed by HPT due to adiabatic heating during the shearing process $^{[27,28]}$ but recent evidence suggests that the inherent heating associated with HPT processing is probably insufficient to initiate dynamic recrystallization ${ }^{[29,30]}$ and instead there is static recrystallization and grain growth due to the moderate melting temperature and low SFE.

The microhardness of the microstructure developed in the center regions of the disks is relatively low even after 5 turns of HPT and storage for 7 years as shown in Figure 2 and this suggests that the microstructure in the center region is affected primarily by the compressive strain applied initially to the disks rather than to the subsequent torsional strain. ${ }^{[31]}$

\subsection{Effect of Self-Annealing on the Hardness Evolution}

The current microhardness measurements demonstrate that, by comparison with samples stored for 1.25 years, long-term storage for 7 years causes further softening of all OFHC Cu samples processed by HPT due to a self-annealing effect. Other studies showed that the self-annealing behavior in metals of medium melting temperatures, such as copper, depended strongly on the amounts of stored energy associated with the densities of lattice defects accumulated during HPT. ${ }^{[21,22]}$ Consequently, the reduction in hardness due to room temperature storage will vary across the samples based on the values of the equivalent strain. 
It was shown earlier in HPT experiments on an austenitic steel that all hardness values may be effectively correlated into a single curve by plotting the individual hardness values against the equivalent strain estimated from equation (1). ${ }^{[32]}$ Figure 5(a) shows this plot for hardness values collected in the present experiments after 1.25 and 7 years but it is readily apparent that there is a sharp trough in hardness values occurring in the very early stages of torsional straining. In order to show these early results more effectively and following a procedure introduced earlier, ${ }^{[14]}$ the same hardness data are replotted in Figure 5(b) with the equivalent strain denoted on a logarithmic scale. Again, it is apparent that both sets of data follow the same general trends but with consistently lower hardness values recorded after storage for 7 years.

These results show that the hardness evolution in OFHC $\mathrm{Cu}$ processed by HPT undergoes three distinct stages of hardening. First, stage I for $\varepsilon_{\mathrm{ev}}<2$ is typical strain hardening due to cold working and the increase in dislocation density. Second, stage II is an unusual softening which occurs at moderate HPT strains, typically $2 \leq \varepsilon_{\mathrm{ev}} \leq 8$, due to the development of an inhomogeneous structure. Third, stage III at $\varepsilon_{\mathrm{ev}}>8$ corresponds to an increase in hardness with increasing equivalent strain leading to a saturation hardness with a reasonably homogeneous and semi-stable UFG structure of high-angle boundaries.

The drop in hardness in stage II is attributed to the onset of recrystallization that was apparent near the disk edge at small HPT strains and then moved inwards towards the center of the disk with further straining. ${ }^{[14,15]}$ Such a drop in hardness is also associated with the increase in the average grain size and in the fraction of HAB and $\Sigma 3$ boundaries. An earlier report showed that such a softening occurred for samples processed by 1 turn within a week of storing at room temperature and the softening increased with increasing storage time to 6 weeks. $^{[15]}$ On the other hand, this short-term self-annealing also showed that there were no changes in the hardness for samples processed by 5 or more turns. These results demonstrate that the amount of imposed strain during HPT leads to the development of an unstable transitional microstructure which occurs in Stage II between the conventional cold-work 
microstructure with a large fraction of LAB in Stage I and the homogeneous UFG microstructure with a large fraction of HAB in stage III.

\subsection{Factors Affecting the Long-Term Thermal Stability of OFHC Cu Processed by HPT}

The results available to date provide clear evidence that the time of storage plays an important role in determining the stability of the microstructure and the hardness in OFHC $\mathrm{Cu}$ after HPT. In the earliest studies on microstructural evolution and hardness homogeneity in high purity copper processed by HPT, the results appeared to confirm that, as in most conventional metals and alloys, ${ }^{[12]}$ there were basically two possible stages associated with the hardening behavior ${ }^{[15,33-39]}$. In the first and initial stage, the hardness increases gradually with increasing equivalent strain due to strain hardening and a UFG microstructure is developed consisting of a uniform array of equiaxed grains separated by HABs. With further HPT straining, there is a transition to a second stage in which the microhardness levels off, reaches a steady-state or saturation condition, and any strain hardening is balanced by dynamic recovery and/or dynamic recrystallization.

In practice, it is now known that these earlier experiments had a limitation because the HPT processing was consistently conducted through relatively large numbers of revolutions. Later, and primarily as a consequence of experiments on high purity $\mathrm{Al}^{[40]}$ where it was shown that the evolution of microstructural homogeneity may differ in the very early stages of processing by HPT, additional experiments were conducted where high purity $\mathrm{Cu}$ was processed through fractional numbers of whole HPT revolutions such as $1 / 4^{[14]}$ or $1 / 2^{[41]}$ turn. In these other experiments, ${ }^{[14-17,41-43]}$ the behavior was different and instead there was evidence for a three-stage hardening behavior as fully documented in the present experiments and depicted in Figure 5. For these data, which become evident only when datum points are available at very low imposed strains, there is an intermediate stage which exists between the conventional strain hardening and the saturation stages and in this intermediate stage the hardness drops abruptly. For OFHC Cu, this softening occurs at HPT strains ranging between 
$\sim 2$ to $\sim 8$ where this region correlates directly with the advent of recrystallization and grain growth.

In order to more fully clarify the effect of storage time, the hardness data reported in an earlier study ${ }^{[15]}$ for the HPT of high purity $(99.99 \%)$ copper is replotted against the equivalent strain as shown in Figure 6 where, following the convention in Figure 5, the equivalent strain is plotted on ( $a$ and $b$ ) a linear scale and (c and d) a logarithmic scale. These results cover storage periods of $48 \mathrm{~h}$ and 1 week $(1 \mathrm{~W})$ to 6 weeks $(6 \mathrm{~W})$ and the logarithmic plot in Figure 6(c and d) provides a very clear representation of the overall behavior. First, there is no evidence for any hardness drop for the data recorded after only $48 \mathrm{~h}$ and therefore this is similar to conventional behavior. Nevertheless, for all other samples, stored for durations from 1 to 6 weeks, there is a sharp drop in hardness and all of these drops occur at equivalent strains in the range of $\sim 5-10$. Second, the hardness profiles for samples stored from 1 week to 6 weeks look very similar to the hardness profiles recorded in Figure 5(a) for the OFHC $\mathrm{Cu}$ after storage periods of 1.25 and 7 years. The only significant difference is that the drop in hardness occurs at a slightly higher equivalent strain for the $99.99 \% \mathrm{Cu}$ by comparison with the OFHC $\mathrm{Cu}$. Despite this difference, the results show there is an evolutionary trend such that long-term storage up to at least 7 years has a significantly detrimental effect on the microstructural stability and microhardness homogeneity in $\mathrm{Cu}$ when processing by HPT. Therefore, this must be an important consideration in any future attempts to use, for any practical applications, the highstrength ultrafine-grained, thin/thick films or nanocrystalline copper that can be fabricated using HPT processing or other SPD processes.

\section{Summary and conclusions}

1. Disks of OFHC copper were processed by high-pressure torsion through various numbers of turns at ambient temperature using an applied pressure of $6.0 \mathrm{GPa}$. Following processing, the disks were stored at room temperature and examined after storage times of 1.25 or 7 years. 
2. An ultrafine-grained structure is produced by HPT with a grain size of $\sim 280 \mathrm{~nm}$ near the edge of the disk after 10 turns but the structure coarsens and the microhardness decreases during long-term storage due to recrystallization and grain growth. A grain size of $\sim 700 \mathrm{~nm}$ was recorded near the edge of the disk after processing by 10 turns and storing for 7 years.

3. The hardness values show a three-stage behavior when plotted against equivalent strain with a stage of much lower hardness values over equivalent strains in the range of $\sim 2-8$.

4. The results show that care must be exercised in making use of OFHC $\mathrm{Cu}$ after HPT processing because long-term storage has a detrimental effect on both the microstructure and the hardness.

\section{Acknowledgements}

The authors acknowledge the support provided by the Public Authority of Applied Education and Training and Kuwait University General Facility (Grant No. GE 01/07) for sample preparation, OM and EBSD measurements. This work was supported in part by the European Research Council under ERC Grant agreement no. 267464-SPDMETALS. 


\section{References}

[1] A. P. Zhilyaev, T. G. Langdon, Progress in Materials Science. 2008, 53, 893.

[2] K. Edalati, Z. Horita, Materials Science and Engineering: A. 2016, 652, 325.

[3] A. P. Zhilyaev, B. K. Kim, G. V. Nurislamova, M. D. Baró, J. A. Szpunar, T. G. Langdon, Scripta Materialia. 2002, 46, 575.

[4] A. Zhilyaev, G. Nurislamova, B.-K. Kim, M. Baró, J. Szpunar, T. Langdon, Acta Materialia. 2003, $51,753$.

[5] J. Wongsa-Ngam, M. Kawasaki, T. G. Langdon, Journal of Materials Science. 2013, 48, 4653.

[6] S. Sabbaghianrad, T. G. Langdon, Materials Science and Engineering: A. 2016, 655, 36.

[7] B. B. Straumal, A. R. Kilmametov, A. Korneva, A. A. Mazilkin, P. B. Straumal, P. Zięba, B. Baretzky, Journal of Alloys and Compounds. 2017, 707, 20.

[8] R. Z. Valiev, Y. V. Ivanisenko, E. F. Rauch, B. Baudelet, Acta Materialia. 1996, 44, 4705.

[9] A. P. Zhilyaev, S. Lee, G. V. Nurislamova, R. Z. Valiev, T. G. Langdon, Scripta Materialia. 2001, 44, 2753.

[10] Y. Estrin, A. Molotnikov, C. Davies, R. Lapovok, Journal of the Mechanics and Physics of Solids. 2008, 56, 1186.

[11] S. Sabbaghianrad, T. G. Langdon, Journal of Materials Science. 2015, 50, 4357.

[12] M. Kawasaki, Journal of Materials Science. 2014, 49, 18.

[13] K. J. Al-Fadhalah, S. N. Alhajeri, A. I. Almazrouee, T. G. Langdon, Journal of Materials Science. $2013,48,4563$.

[14] A. I. Almazrouee, K. J. Al-Fadhalah, S. N. Alhajeri, T. G. Langdon, Materials Science and Engineering: A. 2015, 641, 21.

[15] Y. Huang, S. Sabbaghianrad, A. I. Almazrouee, K. J. Al-Fadhalah, S. N. Alhajeri, T. G. Langdon, Materials Science and Engineering: A. 2016, 656, 55.

[16] Y. Huang, S. Sabbaghianrad, A. I. Almazrouee, K. J. Al-Fadhalah, S. N. Alhajeri, N. X. Zhang, T. G. Langdon, Journal of Materials Research and Technology. 2017, 6, 390.

[17] S. N. Alhajeri, A. I. Almazrouee, K. J. Al-Fadhalah, T. G. Langdon, Advanced Engineering Materials. 2018, 20, 1.

[18] W. Gao, A. Belyakov, H. Miura, T. Sakai, Materials Science and Engineering: A. 1999, 265, 233.

[19] N. Lugo, N. Llorca, J. M. Cabrera, Z. Horita, Materials Science and Engineering: A. 2008, 477, 366. 
[20] J. Gubicza, S. V. Dobatkin, E. Khosravi, A. A. Kuznetsov, J. L. Lábár, Materials Science and Engineering: A. 2011, 528, 1828.

[21] K. Edalati, J. M. Cubero-Sesin, A. Alhamidi, I. F. Mohamed, Z. Horita, Materials Science and Engineering: A. 2014, 613, 103.

[22] K. Edalati, Y. Hashiguchi, H. Iwaoka, H. Matsunaga, R. Z. Valiev, Z. Horita, Materials Science and Engineering: A. 2018, 729, 340.

[23] C.-E. Ho, C.-C. Chen, M.-K. Lu, Y.-W. Lee, Y.-S. Wu, Surface and Coatings Technology. 2016, $303,86$.

[24] R. B. Figueiredo, P. H. R. Pereira, M. T. P. Aguilar, P. R. Cetlin, T. G. Langdon, Acta Materialia. $2012,60,3190$.

[25] I. Balasundar, K. R. Ravi, T. Raghu, Materials Science and Engineering: A. 2013, 583, 114.

[26] B. B. Straumal, O. A. Kogtenkova, A. S. Gornakova, V. G. Sursaeva, B. Baretzky, Journal of Materials Science. 2016, 51, 382.

[27] A. P. Zhilyaev, T. R. McNelley, T. G. Langdon, Journal of Materials Science. 2007, 42, 1517.

[28] A. P. Zhilyaev, S. Swaminathan, A. A. Gimazov, T. R. McNelley, T. G. Langdon, Journal of Materials Science. 2008, 43, 7451.

[29] P. H. R. Pereira, R. B. Figueiredo, Y. Huang, P. R. Cetlin, T. G. Langdon, Materials Science and Engineering: A. 2014, 593, 185.

[30] K. Edalati, Y. Hashiguchi, P. H. R. Pereira, Z. Horita, T. G. Langdon, Materials Science and Engineering: A. 2018, 714, 167.

[31] Y. Song, E. Y. Yoon, D. J. Lee, J. H. Lee, H. S. Kim, Materials Science and Engineering: A. 2011, 528,4840 .

[32] A. Vorhauer, R. Pippan, Scripta Materialia. 2004, 51, 921.

[33] Z. Horita, T. G. Langdon, Materials Science and Engineering: A. 2005, 410-411, 422.

[34] K. Edalati, T. Fujioka, Z. Horita, Materials Science and Engineering: A. 2008, 497, 168.

[35] H. Matsunaga, Z. Horita, Materials transactions. 2009, 50, 1633.

[36] K. Edalati, Z. Horita, Materials Transactions. 2010, 51, 1051; X. H. An, S. D. Wu, Z. F. Zhang, R. B. Figueiredo, N. Gao, T. G. Langdon, Scripta Materialia. 2010, 63, 560.

[37] K. Edalati, Z. Horita, Materials Science and Engineering: A. 2011, 528, 7514.

[38] K. Edalati, K. Imamura, T. Kiss, Z. Horita, Materials Transactions. 2012, 53, 123.

[39] K. Edalati, Z. Horita, Materials Science Forum. 2012, 706, 3034. 
[40] C. Xu, Z. Horita, T. G. Langdon, Materials Transactions. 2010, 51, 2.

[41] K. Edalati, Y. Ito, K. Suehiro, Z. Horita, International Journal of Materials Research. 2009, 100, 1668.

[42] J. Xu, J. Li, C. T. Wang, D. Shan, B. Guo, T. G. Langdon, Journal of Materials Science. 2016, 51, 1923.

[43] M. Y. Alawadhi, S. Sabbaghianrad, Y. Huang, T. G. Langdon, Journal of Materials Research and Technology. 2017, 6, 369. 


\section{Figures captions}

Figure 1. Grain boundary reconstruction from EBSD mapping for samples processed by HPT at: (a-c) 1/4, (d-f) 1/2, (g-i) 1, (j-l) 5 and (m-o) 10 turns. Grey lines denote LABs, black lines denote random HABs and red lines represent $\Sigma 3$ boundaries.

Figure 2. Radial profiles of average microhardness of copper samples after HPT and storage for 7 years.

Figure 3. Radial profiles of average microhardness for copper samples after HPT and storage for 1.25 or 7 years for (a) 1/4 turn, (b) 1/2 turn, (c) 1 turn, (d) 5 turns and (e) 10 turns.

Figure 4. Grain boundary reconstructions from EBSD mapping for copper samples processed by HPT for 5 and 10 turns and stored for (a-d) 1.25 years and (e-h) 7 years. Grey lines denote LABs, black lines denote random HABs and red lines represent $\Sigma 3$ boundaries.

Figure 5. Average Vickers microhardness of OFHC $\mathrm{Cu}$ after HPT against equivalent strain after storage for 1.25 and 7 years with strain plotted on (a) a linear scale and (b) a logarithmic scale.

Figure 6. Extracted average Vickers microhardness of $99.99 \% \mathrm{Cu}$ after HPT against equivalent strain after short periods of storage up to a maximum of 6 weeks $(6 \mathrm{~W})$ with strain plotted on (a) a linear scale from 0-30, (b) a linear scale from 0-250, (c) a logarithmic scale from 1-100 and (d) a logarithmic scale from 0.1-1000 : based on an analysis of data presented earlier for storage up to 6 weeks [14]. 


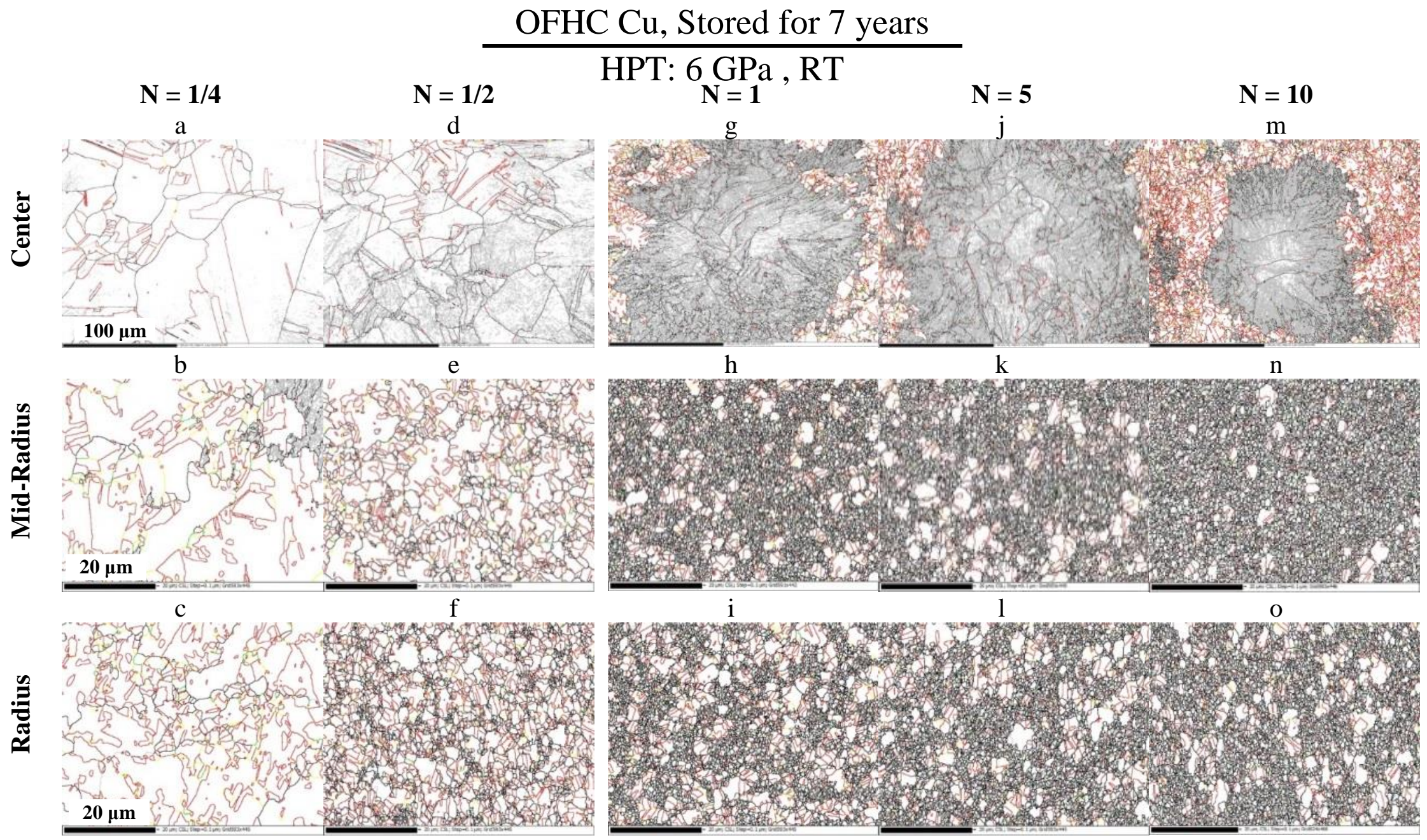

Figure 1. Grain boundary reconstruction from EBSD mapping for samples processed by HPT at: (a-c) $1 / 4,(\mathrm{~d}-\mathrm{f}) 1 / 2$, (g-i) $1,(\mathrm{j}-\mathrm{l}) 5$ and (m-o) 10 turns. Grey lines denote LABs, black lines denote random HABs and red lines represent $\Sigma 3$ boundaries. 


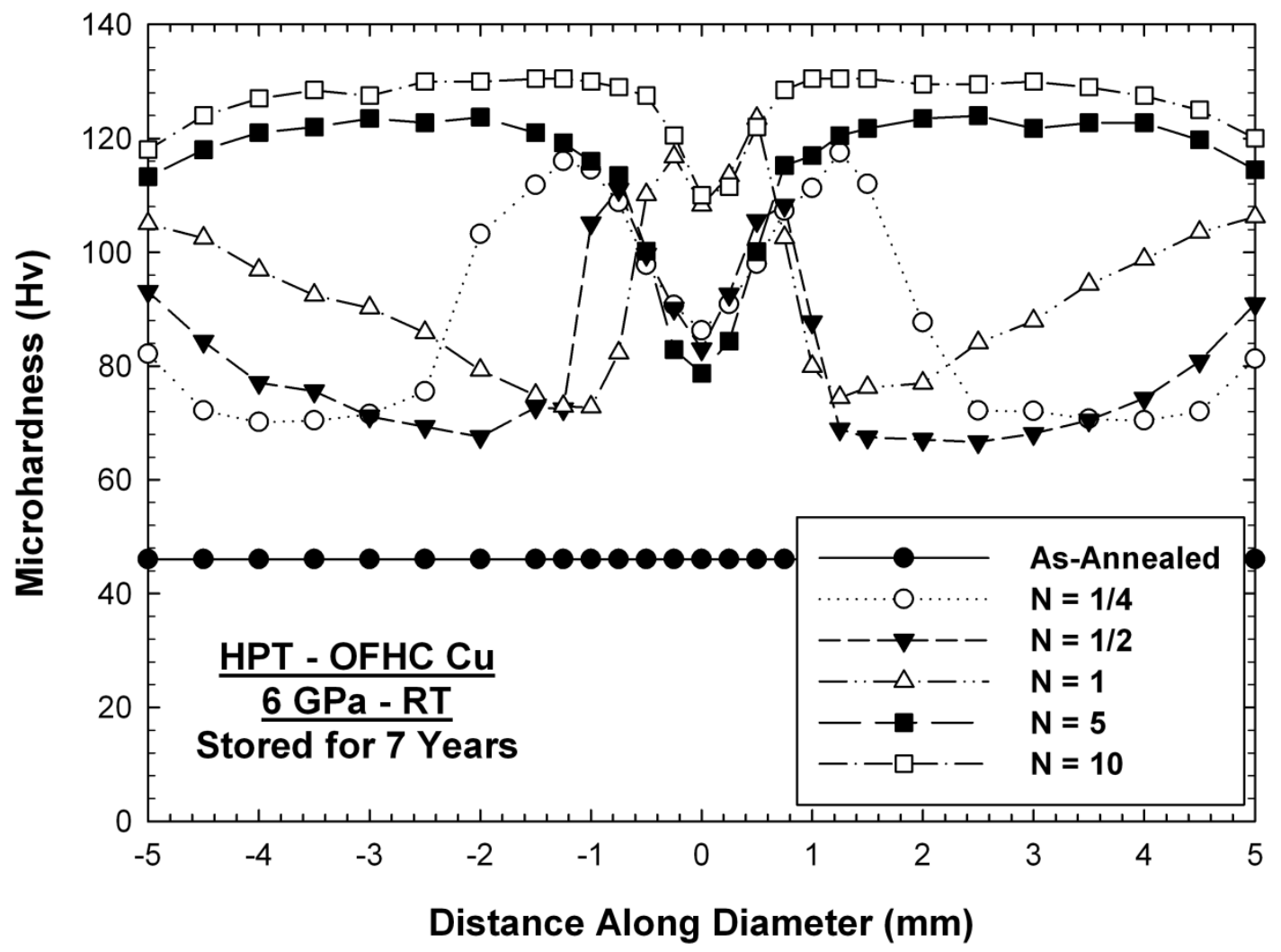

Figure 2. Radial profiles of average microhardness of copper samples after HPT and storage for 7 years. 


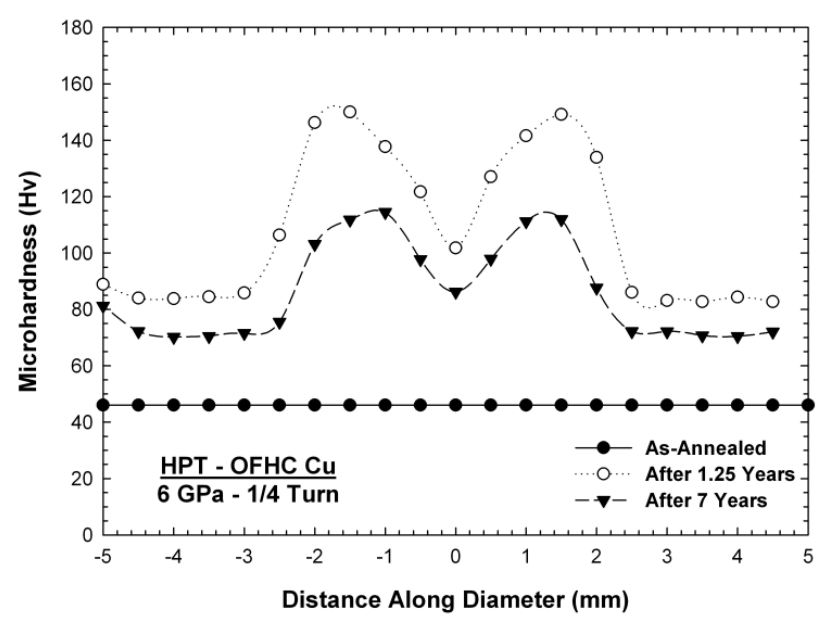

(a)

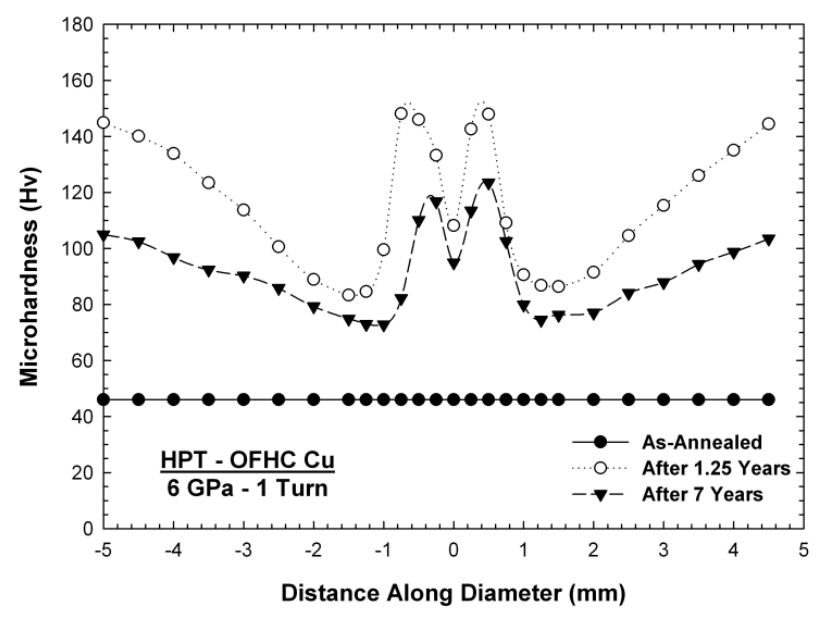

(c)

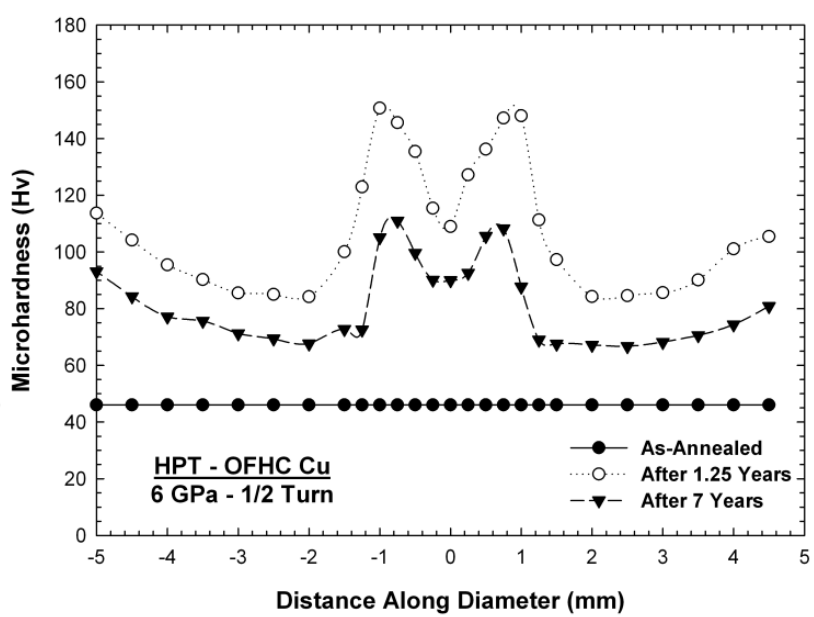

(b)

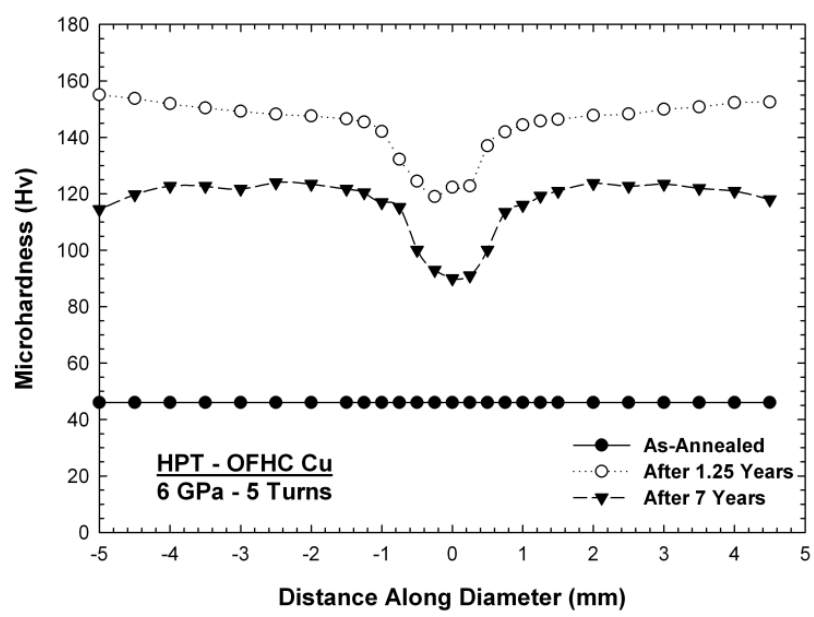

(d)

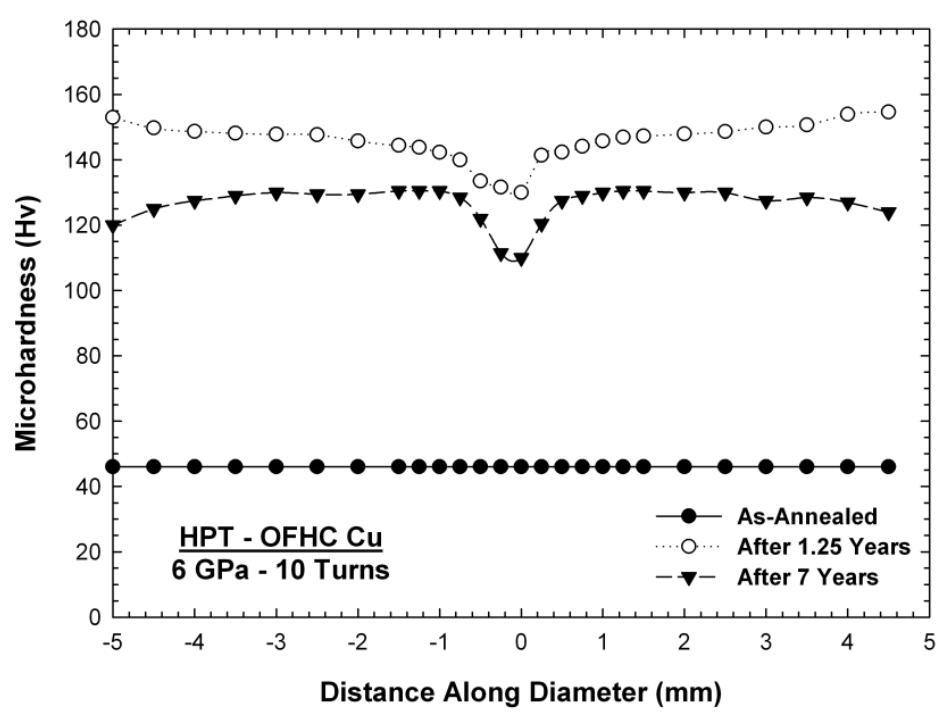

(e)

Figure 3. Radial profiles of average microhardness for copper samples after HPT and storage for 1.25 or 7 years for (a) 1/4 turn, (b) 1/2 turn, (c) 1 turn, (d) 5 turns and (e) 10 turns. 
OFHC Cu Stored for 1.25 and 7 years

HPT: $6 \mathrm{GPa}$, RT

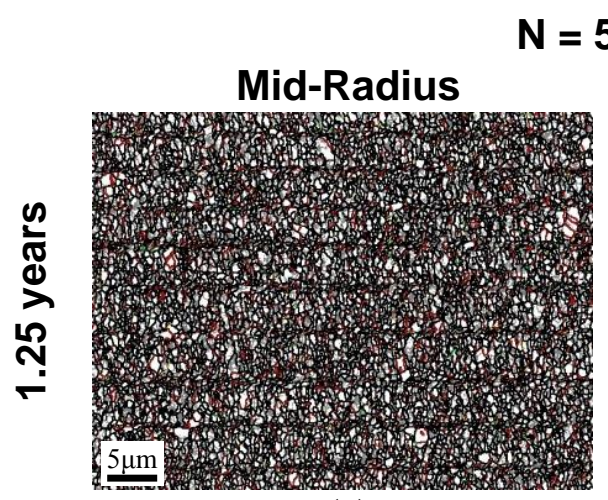

(a)

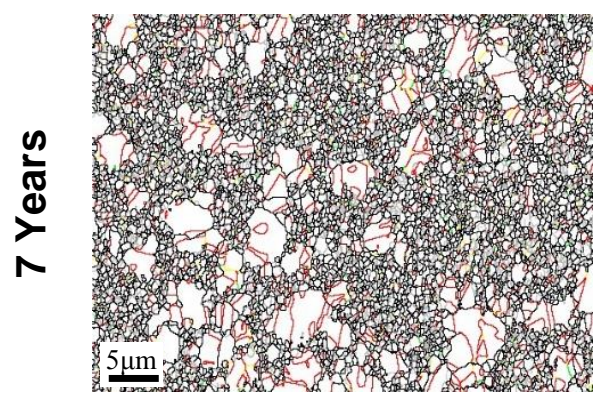

(e)

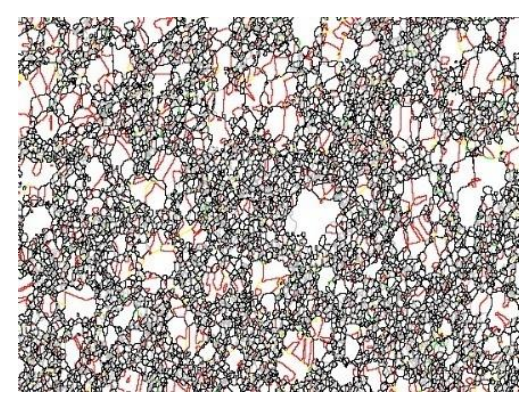

(f)

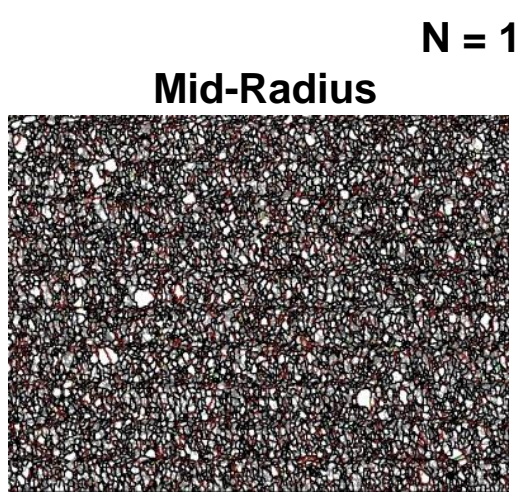

(c)

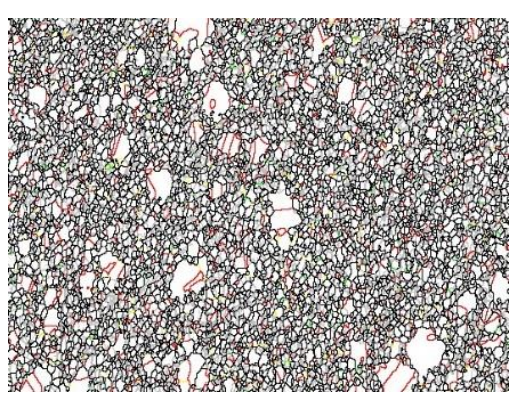

$(\mathrm{g})$

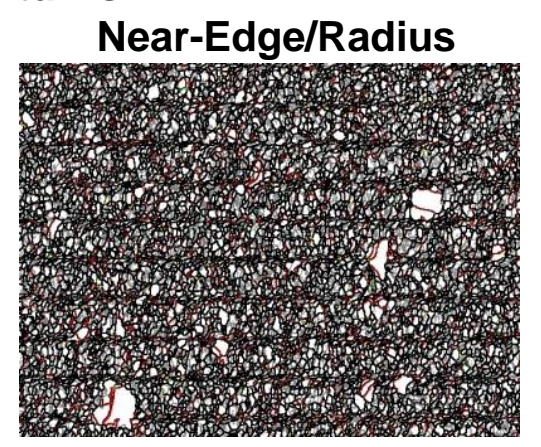

(d)

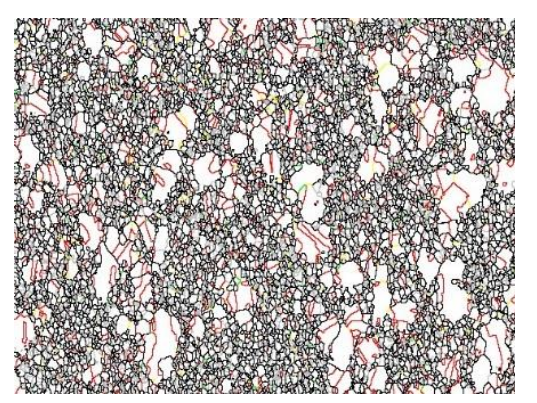

(h)

Figure 4. Grain boundary reconstructions from EBSD mapping for copper samples processed by HPT for 5 and 10 turns and stored for (a-d) 1.25 years and (e-h) 7 years. Grey lines denote LABs, black lines denote random HABs and red lines represent $\Sigma 3$ boundaries. 


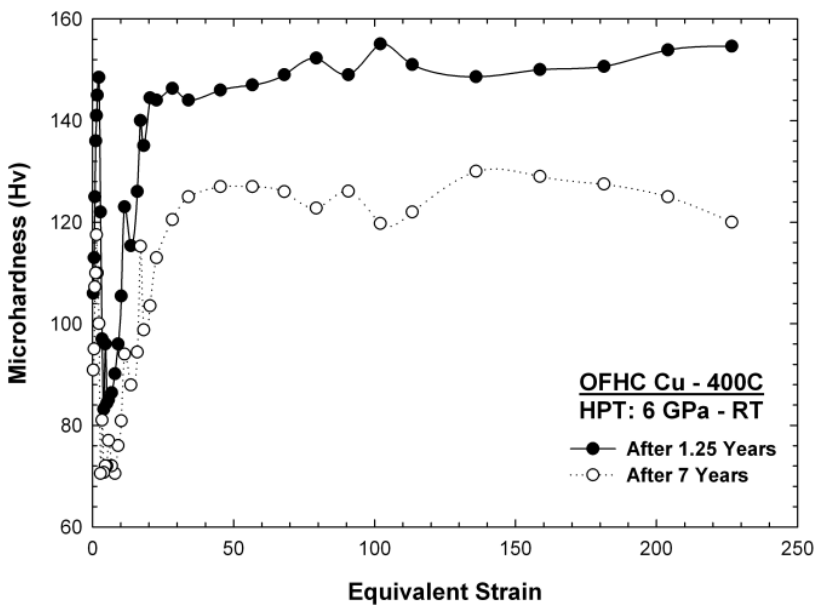

(a)

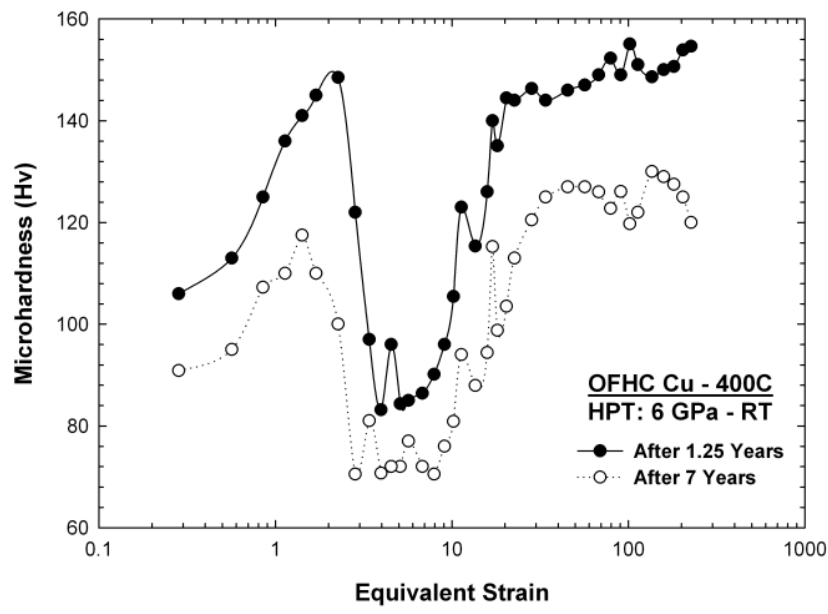

(b)

Figure 5. Average Vickers microhardness of OFHC Cu after HPT against equivalent strain after storage for 1.25 and 7 years with strain plotted on (a) a linear scale and (b) a logarithmic scale. 


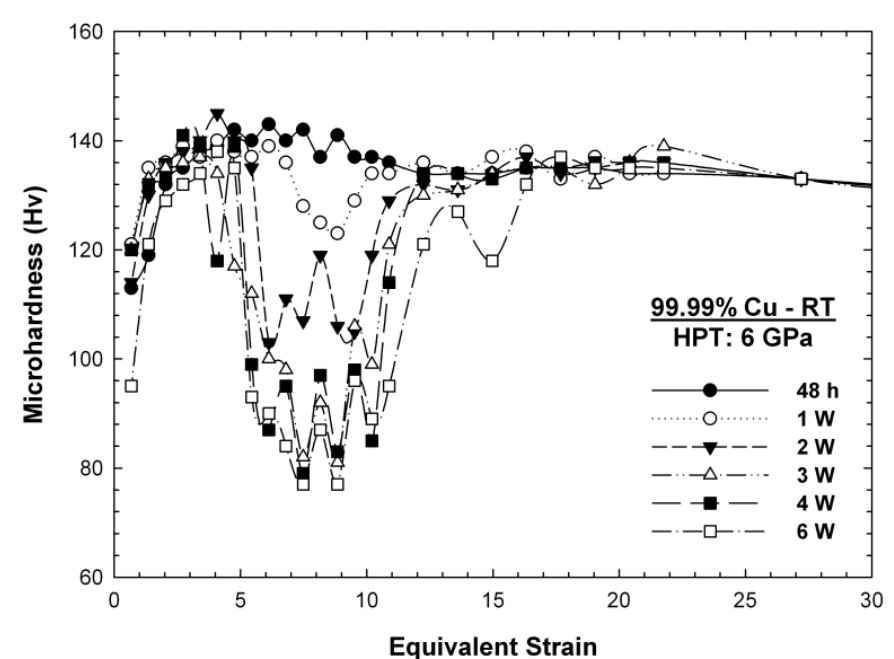

(a)

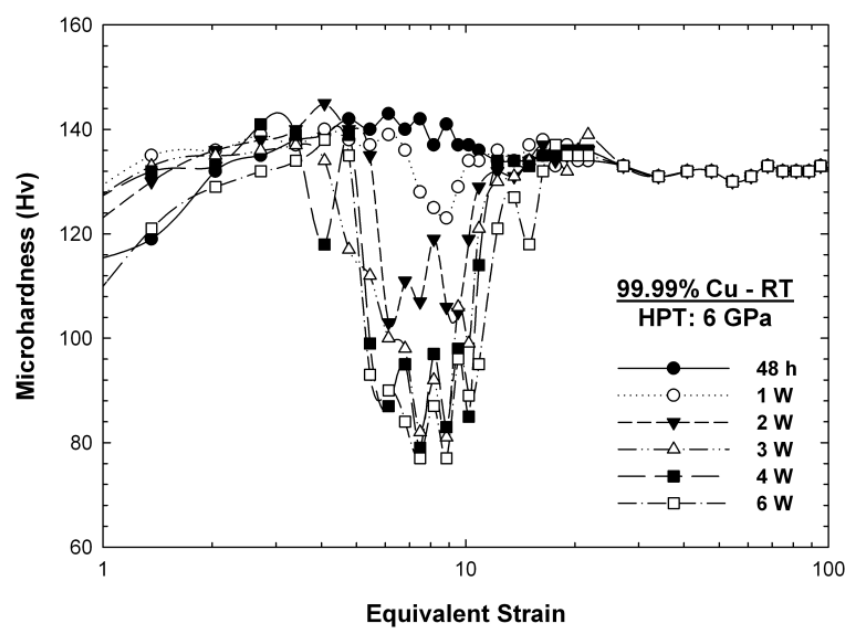

(c)

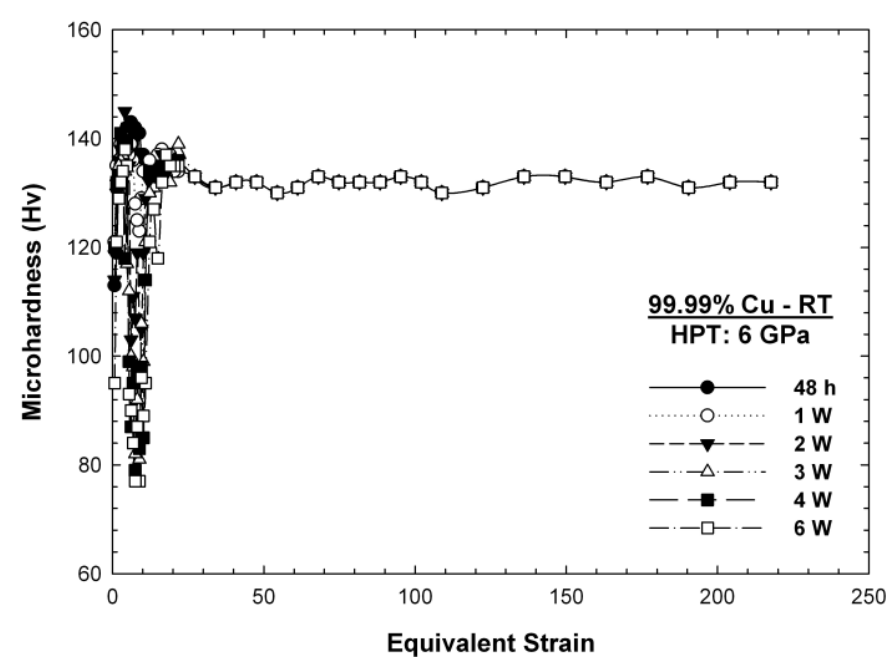

(b)

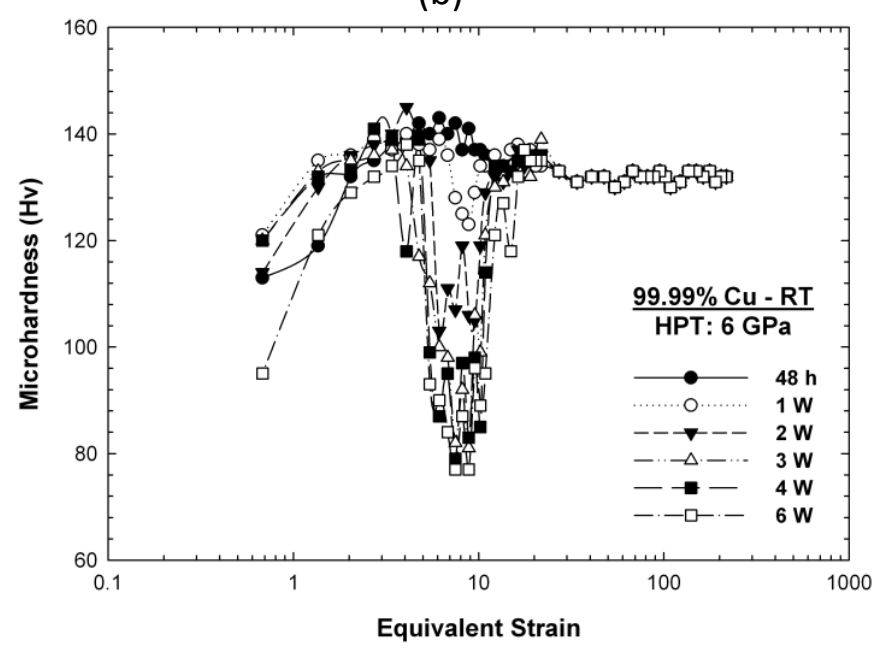

(d)

Figure 6. Extracted average Vickers microhardness of $99.99 \% \mathrm{Cu}$ after HPT against equivalent strain after short periods of storage up to a maximum of 6 weeks $(6 \mathrm{~W})$ with strain plotted on (a) a linear scale from 0-30, (b) a linear scale from 0-250, (c) a logarithmic scale from 1-100 and (d) a logarithmic scale from 0.1-1000 : based on an analysis of data presented earlier for storage up to 6 weeks. ${ }^{[15]}$ 
Table captions

Table 1 Length fractions of HABs and $\Sigma 3$ twin boundaries after storing for 1.25 and 7 years

Table 2 EBSD grain size measurements of HPT $\mathrm{Cu}$ samples after 1.25 and 7 years

Table 1 Length fractions of HABs and $\Sigma 3$ twin boundaries after storing for 1.25 and 7 years

\begin{tabular}{|c|c|c|c|c|c|c|c|c|c|c|c|c|}
\hline \multirow{3}{*}{ Sample } & \multicolumn{4}{|c|}{ Center } & \multicolumn{4}{|c|}{ Mid-radius } & \multicolumn{4}{|c|}{ Radius } \\
\hline & \multicolumn{2}{|c|}{1.25 years } & \multicolumn{2}{|c|}{7 years } & \multicolumn{2}{|c|}{1.25 years } & \multicolumn{2}{|c|}{7 years } & \multicolumn{2}{|c|}{1.25 years } & \multicolumn{2}{|c|}{7 years } \\
\hline & $\sum_{(\boldsymbol{\%})}^{\sum 3}$ & $\begin{array}{c}\text { HAB } \\
(\%)\end{array}$ & $\underset{(\boldsymbol{\%})}{\sum 3}$ & $\begin{array}{c}\text { HAB } \\
(\%)\end{array}$ & $\underset{(\boldsymbol{\%})}{\sum 3}$ & $\begin{array}{c}\text { HAB } \\
(\%)\end{array}$ & $\underset{(\%)}{\sum_{(\%)}}$ & $\begin{array}{c}\text { HAB } \\
(\%)\end{array}$ & $\underset{(\boldsymbol{\%})}{\sum 3}$ & $\begin{array}{c}\text { HAB } \\
(\%)\end{array}$ & $\underset{(\mathbf{\%})}{\sum^{3}}$ & $\begin{array}{c}\text { HAB } \\
(\%)\end{array}$ \\
\hline$N=1 / 4$ & 3.0 & 15.5 & 34.5 & 60.4 & 49.0 & 76.0 & 44.5 & 59.7 & 59.0 & 89.2 & 78.9 & 98.0 \\
\hline$N=1 / 2$ & 3.3 & 13.9 & 5.0 & 17.7 & 55.1 & 82.6 & 50.4 & 96.4 & 13.7 & 69.5 & 33.0 & 92.6 \\
\hline $\mathbf{N}=\mathbf{1}$ & 2.1 & 15.2 & 4.7 & 20.8 & 38.2 & 80.6 & 10.1 & 77.3 & 7.0 & 63.0 & 15.7 & 81.6 \\
\hline$N=5$ & 13.9 & 50.2 & 2.9 & 15.3 & 4.4 & 62.2 & 9.6 & 75.3 & 4.3 & 64.1 & 10.5 & 76.7 \\
\hline $\mathbf{N}=\mathbf{1 0}$ & 5.5 & 33.8 & 14.4 & 30.6 & 4.5 & 56.3 & 5.4 & 70.3 & 4.8 & 56.6 & 8.7 & 74.6 \\
\hline
\end{tabular}

Table 2 EBSD grain size measurements of HPT Cu samples after 1.25 and 7 years

\begin{tabular}{ccccccc}
\hline \multirow{2}{*}{ Sample } & \multicolumn{5}{c}{ Average grain size $(\boldsymbol{\mu m})$} \\
\cline { 2 - 7 } & \multicolumn{2}{c}{ Center } & \multicolumn{2}{c}{ Mid-radius } & \multicolumn{3}{c}{ Radius } \\
\cline { 2 - 7 } & $\mathbf{1 . 2 5}$ years & $\mathbf{7}$ years & $\mathbf{1 . 2 5}$ years & $\mathbf{7}$ years & $\mathbf{1 . 2 5}$ years & $\mathbf{7}$ years \\
\hline $\boldsymbol{N}=\mathbf{1 / 4}$ & 6.8 & 8.6 & 1.2 & 1.7 & 0.7 & 1.6 \\
$\boldsymbol{N}=\mathbf{1 / 2}$ & 5.4 & 5.2 & 0.5 & 1.0 & 0.3 & 0.8 \\
$\boldsymbol{N}=\mathbf{1}$ & 4.7 & 1.6 & 0.4 & 0.6 & 0.3 & 0.6 \\
$\boldsymbol{N}=\mathbf{5}$ & 1.5 & 1.5 & 0.4 & 0.7 & 0.4 & 0.7 \\
$\boldsymbol{N}=\mathbf{1 0}$ & 1.0 & 1.5 & 0.3 & 0.7 & 0.3 & 0.7 \\
\hline
\end{tabular}

